\title{
Inclusão escolar: Atendimento Educacional Especializado, expertise e normalização
}

\author{
School inclusion: specialized educational service, expertise and \\ normalization
}

Patrícia Gräff*

Universidade do Vale do Rio dos Sinos

Daniela Medeiros** Universidade Regional do Noroeste do Estado do Rio Grande do Sul

Resumo Este estudo busca tensionar as balizas que instituem o Atendimento Educacional Especializado (AEE) - no cenário da educação inclusiva - como serviço que re/direciona práticas pedagógicas. Direcionamos o nosso olhar para este atendimento apoiadas em um referencial pós-estruturalista - Nikolas Rose e Michel Foucault -, partindo do pressuposto de que o professor de AEE, na condição de profissional especializado, empreende esforços para diminuir os riscos e normalizar os sujeitos. Assim, organizamos o estudo em três momentos: $A$ escola Contemporânea e o contexto inclusivo, Atendimento Educacional Especializado como expertise normalizadora e Triar e intervir: tarefas do professor de AEE. Inferimos que, constituindo-se como expertise, cabe a este profissional aproximar os sujeitos inclusivos da normalidade, investindo esforços em ações específicas e determinadas para cada sujeito, com vistas a produção de subjetividades cada vez mais inclusivas.

PALAVRAS-CHAVE: Atendimento educacional especializado; Expertise; Inclusão.

Abstract This study aims to pressure the beacons that set the Educational Service Specialist (ESA) - in the scenario of inclusive education - as a service that re/directs pedagogical practices. We direct our looking to this service supported by a post-structuralist framework - Nikolas Rose and Michel Foucault - on the assumption that the ESA teacher, provided specialized professional, undertakes efforts to reduce the risks and normalize the subject. So we organized the study into three periods: The Contemporary and inclusive school context, Specialized Educational Service as normalizing expertise and Screen and intervene: teacher AEE tasks. We infer that, while constituting expertise, it is up to this professional approach inclusive of normal subjects, investing efforts into specific actions and determined for each subject, with a view to producing increasingly inclusive subjectivities.

KEYWORDS: Specialised education service; Expertise; Inclusion. 
"A educação é uma atividade indissoluvelmente implicada com o social"

(VEIGA-NETO, 2011, p. 22) .

Provocadas a pensar as implicações da educação nos modos como a sociedade Contemporânea tem se organizado e as ressonâncias da mesma na vida dos indivíduos, iniciamos estes escritos, direcionando o olhar para a - assim denominada - educação inclusiva. Neste âmbito, interessa-nos provocar alguns tensionamentos ${ }^{1}$ sobre o Atendimento Educacional Especializado (AEE), mais especificamente. Para tal, estabelecemos balizas direcionadoras, a partir dos documentos que normatizam este serviço no Brasil, sejam eles: a) a Política Nacional de Educação Especial na perspectiva da Educação Inclusiva/2008 e b) a Resolução² 04/2009. Assim, este texto pretende problematizar os aspectos da referida legislação que, a nosso entender, oferecem as condições de possibilidade para que o AEE se estabeleça como expertise normalizadora.

$\mathrm{Na}$ tentativa de conduzir o leitor em meio aos argumentos elencados para sustentar tal afirmação, dividimos o texto em três partes assim apresentadas: 1) A escola Contemporânea e o contexto inclusivo, que oferece os contornos para situar à perspectiva inclusiva e o Atendimento Educacional Especializado dentro da circunscrição educacional brasileira; 2) Atendimento Educacional Especializado como expertise normalizadora, onde são discutidos os elementos que permitem a leitura deste serviço como uma das possíveis expertises normalizadoras Contemporâneas, tendo como objetivo principal o gerenciamento do risco; e por fim, 3) Triar e intervir: tarefas do professor de AEE, na qual são tensionadas as funções desenhadas para o professor de AEE nas escolas de ensino regular, colocando-o na posição de expert, em diferentes momentos, frente ao tema da inclusão.

Para empreender o exercício pretendido ao longo deste texto, utilizamo-nos de um aporte teórico de inspiração pós-estruturalista, com ênfase Foucaultiana, que nos permite exercer a suspeita e colocar em suspenso algumas verdades estabelecidas e naturalizadas no contexto educacional.

\section{A escola contemporânea e o contexto inclusivo}

$\mathrm{Na}$ sociedade Contemporânea, a emergência de sujeitos aptos para as dinâmicas de mercado está na pauta do dia. Todos contribuindo com seu corpo, com seu trabalho para sustentar as engrenagens que movimentam o aparelho social. $\mathrm{Na}$ verdade, "não estamos nem nas arquibancadas nem no palco, mas na máquina panóptica, investidos por seus efeitos de poder que nós mesmos renovamos, pois somos suas engrenagens" (FOUCAULT, 2009, p. 205). Na sutileza, na tenuidade de distintos mecanismos de subjetivação são fabricados, quase imperceptivelmente, sujeitos úteis, corpos adaptáveis às demandas da sociedade.

$\mathrm{Na}$ escola são produzidos, diariamente, "sujeitos governáveis através de várias técnicas [...] de controle, normalização e moldagem da conduta” (FIMYAR, 2009, p. 38). O conjunto destas técnicas é entendido e nomeado por Foucault (1992) como governamentalidade. Pela governamentalidade são colocados em operação diferentes mecanismos, oriundos de diversas instituições a fim de moldar os sujeitos. Por meio 
dela é possível perceber-nos como produto de distintas forças em nós atuantes, bem como daquelas de nós oriundas. Ou seja, somos o resultado de sutis, porém complexos, jogos de poder, de regimes de verdade ${ }^{3}$ estabelecidos para e por cada um de nós. Engendrados nas tramas da sociedade e, mais especificamente da educação, fabricamonos uns aos outros.

Nesta linha, a escola figura como principal aparelho de disciplinarização e controle. No espaço/maquinaria ${ }^{4}$ escolar são produzidos sujeitos úteis às demandas de mercado, entendendo que, capazes de consumir e sustentar seu consumo, todos estariam incluídos na sociedade. Nesta esteira, são colocados diariamente em operação discursos e práticas escolares, que, com o advento da educação inclusiva, tem se ocupado, também, dos sujeitos público-alvo da Política Nacional de Educação Especial na perspectiva da Educação Inclusiva (2008). Desde 2008, as escolas têm sido convidadas a contribuir para a governamentalidade de todos, inclusive daquela parcela da população que, pelos mais diversos fatores, não tinha direito à educação no ensino regular. Entende-se que as políticas de inclusão "só se realizarão plenamente se e quando todos os corpos - pensados como normais e anormais - forem colocados juntos, num mesmo espaço" (VEIGA-NETO; LOPES, 2007, p. 958). Reunindo todos em um mesmo lugar - a escola - ampliam-se as possibilidades de governamento. Ninguém escapa, o controle é potencializado pela intervenção exercida na vida de cada um.

Controlar para governar em um movimento em que "as relações de força constituem o poder" e este "não se ancora numa instituição, não se apoia em nada fora de si mesmo, a não ser no próprio diagrama estabelecido pela relação diferencial de forças" (VEIGA-NETO, 2011, p. 130). Um processo que só funciona porque os sujeitos inclusivos ${ }^{6}$ estão convencidos de que esse é o melhor caminho. A maquinaria colocada em operação atua sobre cada indivíduo, persuadindo-o sobre a necessidade da inclusão e produzindo nele o desejo pela sua permanência, para que busque e produza, por si, as condições para manter-se incluído. A política de inclusão emerge, assim, como forma de convencimento de que este movimento de fato é o melhor para todos.

Contudo, corre-se o risco (talvez desejado por tais políticas) do apagamento ou invisibilização das diferenças. Inclusão e normalização parecem andar de mãos dadas, produzindo ressonâncias nos corpos e nas almas dos sujeitos inclusivos. Sua meta pode ser lida nas práticas cotidianas colocadas em operação na escola. Aproximar os sujeitos, diluindo-os no conjunto de alunos, misturando-os aos outros, permite que se tornem mais iguais a eles, uniformiza-os de modo a atenuar suas diferenças. Aqueles que estavam fora, em outro lugar, ou em um entre-lugar, agora possuem o direito (ou dever) de ocupação deste espaço comum.

Deste modo, a escola comum/inclusiva empreende estratégias que consistem em “'ingerir', 'devorar' corpos e espíritos estranhos de modo a fazê-los, pelo metabolismo, idênticos aos corpos que os ingerem, e, portanto não distinguíveis deles" (BAUMAN, 2001, p. 118). Ou seja, a inclusão torna os escolares, massa homogênea, uniforme e passível de modelagem a partir de técnicas específicas e direcionadas a todos. Ali, todos dispõem de condições lineares para a aprendizagem, sem segregação espacial. Incluídos, embora sem identidade própria, sem diferença, todos iguais. 
Quando alguma diferença se desprende do emaranhado homogêneo constituído nas salas de aula, é imediatamente observada e encaminhada para avaliação no AEE. Aqueles que manifestam algum comportamento e/ou característica destoante da norma estabelecida para o contexto escolar, são encaminhados para o minucioso escrutínio a ser praticado pelo professor de AEE. Quando este consegue enquadrar o aluno em uma das categorias estabelecidas pela Política (2008), inicia-se o processo de normalização do mesmo. Para aprofundar a questão, a seção seguinte discutirá a produção deste serviço como expertise normalizadora, que se constitui por meio de um conjunto de técnicas e estratégias que visam, ao fim e ao cabo, normalizar o sujeitos, gerenciando o risco social.

\section{Atendimento Educacional Especializado como expertise normalizadora}

A formatação do Atendimento Educacional Especializado, nos moldes de uma expertise normalizadora emerge deste cenário obcecado pelo controle e no qual todos precisam estar incluídos. Para viabilizar a educação para todos, serviços específicos têm sido formulados por organismos governamentais e colocados em operação nos meios escolares, orientados por diversos documentos que balizam/direcionam as práticas ali exercitadas, começando pela referida Política (2008) e perpassando decretos, resoluções e notas técnicas específicas à organização da Educação Especial. Percebe-se nestes documentos o acento na oferta do Atendimento Educacional Especializado (AEE), de forma a assegurá-lo e moldá-lo como garantia para a inclusão de todos. A investida neste serviço - e no profissional que o exerce - emerge como principal ponto de sustentação das políticas de inclusão, orientando as ações dos grupos escolares com vistas à inclusão, o que remete a uma economia característica à governamentalidade, potencializando os efeitos e "diminuindo o custo econômico" (FOUCAULT, 2009, p. 78).

Empoderando os professores que ocupam as salas de recursos multifuncionais, o Estado os coloca na posição de centralidade de todo o processo inclusivo, aspecto que será aprofundado na última parte deste texto. Não há ação que escape aos seus olhos. A eles recorrem todas as instâncias da escola quando se trata da inclusão. Assim se configura a expertise, por meio de "perícia, avaliação ou comprovação realizada por experto" (FERREIRA, 2004). O experto da vez é o professor de AEE, a quem é conferido o conhecimento acerca das questões referentes à inclusão. Contudo esta não é a única característica que lhe cabe, associada à expertise, atribui-se a ele a incumbência da normalização. Nas operações de normalização

[...] - que implicam tanto trazer os desviantes para a área da normalidade, quanto naturalizar a presença de tais desviantes no contexto social onde circulam - devem ser minimizadas certas marcas, certos traços e certos impedimentos de distintas ordens. Para isso, vê-se a criação, por parte do Estado, de estratégias políticas que visam à normalização das irregularidades presentes na população. (LOPES, 2009, p. 160). 
O Atendimento Educacional Especializado constitui-se parte integrante deste conjunto de estratégias políticas que visam à normalização. Cabe a ele a tarefa de capturar os sujeitos que escapam da normalidade e disponibilizar "recursos de acessibilidade e estratégias que eliminem as barreiras para sua plena participação na sociedade e desenvolvimento de sua aprendizagem" (BRASIL, 2009, s/p, grifo nosso). Ou seja, ao $\mathrm{AEE}$ compete a criação/invenção de recursos e técnicas que fabriquem sujeitos inclusivos, tornando-os, tanto quanto possível, parecidos com aqueles considerados normais. Com suas ferramentas e estratégias, o AEE permite que eles (os sujeitos inclusivos) possam, juntamente com todos os outros, acessar os meios de que a escola dispõe para a sua participação e permanência, projetando-os para a vida em sociedade, sendo úteis para ela.

"Desenha-se a rede de olhares que se controlam uns aos outros" (Foucault, 2009, p. 144). Para tornar estes sujeitos governáveis, faz-se necessário "agir sobre aquele que abriga, dar domínio sobre seu comportamento, reconduzir até eles os efeitos do poder, oferecê-los a um conhecimento, modificá-los" (Ibidem, p. 144). No intuito de alcançar a tão desejada normalização, as políticas públicas que regem o processo de educação inclusiva na sociedade Contemporânea, são desenhadas na perspectiva da governamentalidade e com isso "a definição do conceito de educação inclusiva como norma passa a funcionar como uma estratégia de dominação, [de forma a definir aquele que] deve estar dentro ou fora da lista das alteridades permitidas" (LOPES, 2012, p. 8). Assim, "seja ou não trazida para dentro da norma, ela é a confirmação da regra" (GALLO, 2009, p. 8).

Neste sentido, o profissional responsável pelo AEE traz como tarefa conduzir tais sujeitos à linha da normalidade. Para atender a estes fins - normalizar e governar -, "o corpo é investido por relações de poder e de dominação" (FOUCAULT, 2009 , p. 25). Poderes que emanam, principalmente, daquele que se encontra na posição de experto. $\mathrm{Na}$ escola inclusiva, é o professor de AEE quem se situa na centralidade do poder sobre os sujeitos inclusivos, determinando lugares e possibilidades para eles. Assim como no Panóptico (FOUCAULT, 2009) um único olhar vigilante seria capaz de controlar a todos e manter a seguridade; na escola inclusiva, um único educador especial - professor de AEE - seria suficiente para manter sob vigilância e controle todo um grupo de professores e escolares. Posto que, como sinaliza a Política, a educação especial, como modalidade que atravessa todas as etapas, níveis e modalidade de ensino, "realiza o atendimento educacional especializado, disponibiliza os serviços e recursos próprios desse atendimento e orienta os alunos e seus professores quanto a sua utilização nas turmas comuns do ensino regular" (2008, p. 16, grifo nosso). Enfim, a educação especial, por meio do $\mathrm{AEE}$, funciona como um poderoso agente de inclusão, garantindo o controle de todos, normalizando-os, implicitamente.

Compete, então, ao AEE significativa contribuição na fabricação de corpos/ sujeitos dóceis (FOUCAULT, 2009), habilitados a permanecer, juntamente com os colegas, no espaço de sala de aula, para ali munir-se das ferramentas necessárias a sua inclusão. Tornando-se úteis, capazes de consumir e manter-se no "jogo econômico do neoliberalismo" (LOPES, 2009) estarão, também eles, aptos para integrar a sociedade contemporânea. Vislumbra-se um "quadriculamento cada vez mais detalhado 
dos comportamentos individuais, [e com isso as instituições disciplinares passam a produzir uma] maquinaria de controle" (FOUCAULT, 2009, p. 145), que funciona como um microscópio de comportamento. A inclusão como possibilidade de controle e normalização.

Segundo Foucault, diferentes sujeitos são colocados "no interior do exterior, e inversamente [...], prisioneiros no meio da mais livre, da mais aberta das estradas, solidamente acorrentados à infinita encruzilhada, [surgem como um] passageiro por excelência, isto é, o prisioneiro da passagem" (DELEUZE, 2006, p. 104). Ao incluir os sujeitos em um sistema comum de ensino, constituído por regras, normas e ideais de comportamento e disciplina, tais sujeitos passam a ser submetidos a aprisionamentos e a formatação de atitudes desejáveis, ou seja, suas condutas passam a ser conduzidas pelos padrões estabelecidas nestes espaços. Com esse intuito, passa-se a construir estratégias de correção de tudo aquilo que não se tolera na escola inclusivo e assim aproxima-se estes sujeitos da linha da normalidade.

A fim de clarificar a ideia sobre quem são estes sujeitos inclusivos, a Política (2008) esclarece o público alvo do AEE: "alunos com deficiência, transtornos globais do desenvolvimento e altas habilidades/superdotação". Cabe ainda ao profissional experto, "orientar os sistemas de ensino para promover respostas às necessidades educacionais especiais". De acordo com este documento, aqueles sujeitos apontados como inclusivos precisam inicialmente/obrigatoriamente ser enquadrados em um dos três grandes grupos que compõe o público alvo do AEE, aproximando-se entre si por alguma característica ou traço específico. Com isso, "é possível ter a identificação do normal e do anormal, bem como das diferentes curvas de normalidade"(LOPES, 2009, p. 160). O sujeito é sempre visto a partir de um outro, de uma ideia de comparabilidade, nunca a partir de si mesmo.

Exercendo a função de expertise normalizadora, o AEE classifica e normaliza os sujeitos - determina quais os sujeitos podem ser enquadrados nas categorias pré-estabelecidas para o público-alvo da educação inclusiva - a partir de um (suposto) conhecimento específico, operado por meio de um conjunto de técnicas e estratégias destinadas ao exame e posterior intervenção normalizadora junto aos sujeitos que não se encaixam nos gradientes de normalidade, os anormais. Dito de outro modo, a inclusão é potencializada na escola pela intervenção do $\mathrm{AEE}$ como expertise normalizadora.

O AEE encontra-se, assim, intimamente implicado com as Políticas Inclusivas, com a finalidade de estabelecer a normalidade. Desta forma, os sujeitos inclusivos, após serem identificados/nomeados como tal, passam a ser alvo das práticas de normalização como possibilidade de fazer parte deste grande grupo que já compõe a escola comum. "Ao estarem incluídas nos grupos as pessoas tornam-se alvos fáceis das ações do Estado" (LOPES, 2009, p. 153). Explicitam-se práticas de um jogo de ações que tem por objetivo "conduzir as condutas humanas dentro de um jogo com regras definidas, no interior dos distintos e dos muitos grupos sociais" (Ibidem, p. 153).

Ao trazer todos para dentro, assumindo uma política da educação para todos, a escola funciona como agente no gerenciamento do risco social. Regulando os sujei- 
tos inclusivos, conduzindo as suas condutas, a escola diminui os riscos de tais sujeitos se tornarem improdutivos e passarem a depender de políticas de assistência, gerando custos para o Estado. "É preciso agir sobre cada indivíduo para conseguir alcançar o governo no plano da população, evitando e reduzindo ou extinguindo a ameaça que tal sujeito representa à sociedade e à vida coletiva" (LOCKMANN; TRAVERSINI, 2011, p. 37).

Por meio da triagem e da intervenção junto aos sujeitos inclusivos, a escola contribui para a diminuição dos riscos por duas vias: pela inclusão de tais sujeitos nas estatísticas, o que torna possível uma série de ações sobre eles, pelas políticas públicas; e pelas práticas escolares exercidas sobre eles. Este segundo campo será alvo das problematizações lançadas na última parte do texto, colocando ênfase nas atribuições do professor de AEE, sem esquecer que, "ao fim e ao cabo a inclusão escolar tem em seu horizonte a diminuição do risco social” (VEIGA-NETO; LOPES, 2007, p. 949).

\section{Triar e intervir: tarefas do professor de AEE}

$\mathrm{Na}$ Contemporaneidade temos visto emergir alguns deslocamentos de ênfase importantes no contexto social e que se intercambiam com as práticas empreendidas na escola. Nikolas Rose - em entrevista à Physis Revista de Saúde Coletiva - lança o alerta para um destes deslocamentos de ênfase na área da saúde dizendo: "o que vemos emergir aqui, tal como em tantas outras áreas, é o que chamo de "triar (screen) e intervir' e não mais 'disciplinar e punir”' (2010, p. 313). Triar, avaliar, escrutinar, enquadrar e intervir, são ações que se encaixam perfeitamente ao cotidiano da escola inclusiva.

Triagens são realizadas rotineiramente pelo professor de AEE. Aquele aluno que não acompanha o ritmo dos colegas, aquele que não aprende como deveria, $o$ outro que não presta atenção, distrai-se com frequência, não responde aos estímulos oferecidos pelo professor, não se comporta de acordo com as normas estabelecidas, enfim, desvia de alguma forma do padrão estabelecido para os escolares. Tais queixas são frequentemente observadas nos encaminhamentos destinados ao professor de AEE. Pautado nelas, tal profissional realiza o exame minucioso do indivíduo para que possa, com alguma segurança, enquadrá-lo em uma das três categorias estabelecidas para o público-alvo deste serviço, ou mantê-lo no apaziguador espectro da normalidade.

Realizada a triagem e o enquadramento do sujeito em um dos grupos de anormalidade pré-estabelecidos - lembrando que para ser inclusivo só há três possibilidades - o profissional responsável pelo AEE inicia o processo de intervenção, colocando em operação algumas estratégias para a promoção do processo de inclusão destes alunos. Cabe a este profissional, além dos atendimentos oferecidos aos alunos no turno inverso à aula regular (como é explicitado na Política de 2008), garantir, de alguma forma, que este processo ocorra de forma tranquila. Diminuir as possibilidades de questionamento e dúvida quanto à efetivação da inclusão, por meio do trabalho conjunto com os demais profissionais que atuam junto ao sujeito inclusivo, tranquilizando e exercendo o controle sobre todos é uma das atribuições do professor do Atendimento Educacional Especializado, estabelecidas pela Resolução no 04/2009 em seu artigo 13, incisos I a VIII, que, na sequência, serão discutidos um a um. 
No inciso "I - identificar, elaborar, produzir e organizar serviços, recursos pedagógicos, de acessibilidade e estratégias considerando as necessidades específicas dos alunos público-alvo da Educação Especial”, podemos observar os contornos que se desenham para a sua função na escola, enfatizando a centralidade que lhe é conferida desde a avaliação/triagem, até a operacionalização das práticas pedagógicas dentro da sala de aula, por meio das estratégias que the cabe prover, para que o professor disponha dos recursos pedagógicos adequados as necessidades de cada aluno inclusivo.

As atividades a serem exercidas pelo professor de AEE, nos atendimentos individuais ou em grupos, precisam ser discriminadas no Plano de AEE, conforme prescreve o inciso II do mesmo artigo: "elaborar e executar plano de Atendimento Educacional Especializado, avaliando a funcionalidade e a aplicabilidade dos recursos pedagógicos e de acessibilidade", que o investem da expertise que conhece a função e o desempenho esperado pelos mais variados recursos pedagógicos e de acessibilidade e desempenha avaliação permanente dos mesmos, mantendo-se vigilante a qualquer desvio.

Ele (o professor de AEE) continua sendo colocado na posição de experto no inciso III, que lhe atribui como função: "organizar o tipo e o número de atendimentos aos alunos na sala de recursos multifuncionais", atividade para a qual se faz necessário conhecimento acerca dos tipos específicos de anormalidade, a fim de que possa agrupá-los por afinidades ou destinar-lhes atenção individual, de acordo com cada caso.

No inciso IV - "acompanhar a funcionalidade e a aplicabilidade dos recursos pedagógicos e de acessibilidade na sala de aula comum do ensino regular, bem como em outros ambientes da escola", a expertise volta a ser expandida para além da sala de recursos multifuncional e invade novamente o espaço da sala de aula e demais ambientes da escola, desta vez para avaliar e controlar os usos que têm sido feitos daqueles recursos propostos desde o inciso I.

Não satisfeito com a intervenção do profissional responsável pelo AEE no espaço escolar, o Estado the atribui, no inciso V, a função de "estabelecer parcerias com as áreas intersetoriais na elaboração de estratégias e na disponibilização de recursos de acessibilidade", ou seja, ampliam-se as formas de intervenção e controle sobre sujeito inclusivo, por meio da articulação com as demais áreas, possibilitando o escrutínio de todos os aspectos de sua vida. O empoderamento deste profissional na escola é potencializado a medida que aumenta a rede de expertises que atuam sobre o sujeito inclusivo, posto que é ele quem, cada vez mais, detém informações sobre cada um dos âmbitos que participam da rede, isto é, cada vez mais os professores e familiares precisam recorrer a ele para obter informações sobre o sujeito.

Sendo o professor de AEE o centro para o qual convergem todas as informações sobre o sujeito inclusivo, não poderia ser outro o profissional responsável por, de acordo com o inciso VI, "orientar professores e famílias sobre os recursos pedagógicos e de acessibilidade utilizados pelo aluno". Ele detém o conhecimento sobre todos os recursos utilizados pelo aluno e sobre aqueles indicados para ele, assim, orienta e 
regula os usos de cada um deles, seja no espaço da escola, seja no espaço familiar, ensinando, inclusive, professores, familiares e o próprio sujeito inclusivo, sobre os seus usos, conforme prescreve o inciso VII: "ensinar e usar a tecnologia assistiva de forma a ampliar habilidades funcionais dos alunos, promovendo autonomia e participação".

O último inciso deste artigo 13 coloca mais uma vez o acento na necessidade de parceria entre o professor de AEE e os professores do ensino regular. O inciso VIII determina como atribuição do professor de AEE, "estabelecer articulação com os professores da sala de aula comum, visando à disponibilização dos serviços, dos recursos pedagógicos e de acessibilidade e das estratégias que promovem a participação dos alunos nas atividades escolares", e fecha o ciclo de atuação deste profissional, visibilizando a sua centralidade em todas as ações referentes à educação inclusiva, seja no âmbito do AEE, da sala de aula regular, da família ou de outras áreas que atuem de forma conjunta com este profissional.

Garantindo o controle e a tranquilidade, o professor de AEE associa expertise à normalização. Trazendo todos para a linha da normalidade, sem fugas demasiadamente aparentes, com suas diferenças minimizadas ou completamente invisibilizadas, todos são convencidos que tal profissional tem realizado sua função com êxito e o processo inclusivo tem ocorrido conforme explicitado nos documentos que o regem.

Além destas tarefas diárias, cabe a tal profissional, conversar/orientar professores, auxiliares, familiares, encontrando momentos para reunir-se com outros profissionais que estejam envolvidos com estes alunos. Desta forma, é atribuída a ele a responsabilidade por disseminar, de alguma forma, suas compreensões e conhecimentos, realizando momentos de formação com os demais docentes da escola.

Apesar de muitos outros sujeitos comporem este círculo inclusivo, este profissional parece emergir como o experto da vez. A ele é conferido um empoderamento de saberes e poderes, os quais permitem viabilizar a efetivação das Políticas vigentes. Tal empoderamento, em forma de expertise, aparece como resultado de uma economia de governo. Este profissional passa a constituir as redes de poder estabelecidas, sendo produzido como responsável por garantir a efetivação e convencimento das estratégias (por ele) estabelecidas.

\section{Amarrações}

No início dos escritos, ao problematizar sobre a escola Contemporânea e o contexto inclusivo, tentamos dar visibilidade a estes jogos de poder que constituem a rede inclusiva e são definidos por todos estes indivíduos que a compõe de alguma forma. Todos contribuem de alguma maneira para conservar as engrenagens deste sistema/maquinaria. Ao serem submetidos a estes jogos e convencidos a deles participar, a governamentalidade encontra maiores possibilidades de se fazer. Colocando todos em um mesmo espaço, são abertas possibilidades de controle e, assim, todos se compõem e são compostos no resultado de jogos de poder e regimes de verdade.

Deparamo-nos, então, com a escola. A esta cabe disciplinar e controlar, por meio de um processo de normalização de corpos, tornando-os aptos a atuarem na 
sociedade. A escola se vê convidada a colaborar com a governamentalidade. Para tanto, o Estado encarrega-se de definir suas responsabilidades, bem como, determinar os sujeitos aptos a constituir este grupo.

Diferentes documentos, como a Política de 2008, decretos, resoluções e notas técnicas específicas têm direcionado as práticas e sustentado as políticas inclusivas. Junto a isso, mantém-se a ideia da expertise conferida ao professor do AEE. Cabe a este profissional a responsabilidade pela normalização e efetivação dos objetivos lançados nos referidos documentos. A Política que prevê uma educação para todos opera com a funcionalidade de gerenciamento do risco social, regulando os sujeitos e conduzindo suas condutas. Estes por sua vez, passam a fazer parte deste jogo de forças, tendo suas condutas direcionadas por meio da ocupação de um lugar de dependência destas políticas.

Finalmente, em Triar e intervir: tarefas do professor de AEE, lançando-nos sobre as teorizações empreendidas por Nikolas Rose, capturando o conceito por ele elaborado, qual seja: triar e intervir e o direcionamos ao contexto da escola inclusiva. Tal perspectiva permite pensar nas triagens que o professor do AEE realiza sobre os diferentes sujeitos que constituem o ambiente escolar e que por algum motivo passam a integrar o grupo da educação especial. O movimento de triagem é seguido pela intervenção e todo aquele que venha a se encaixar neste público alvo do $A E E$ é submetido a este jogo de intervenções, as quais trazem como função aproximá-lo da linha da normalidade. Assim, a Resolução no 04/2009 em seu artigo 13, incisos I a VIII, confere a este profissional o lugar de experto, capaz de identificar estes sujeitos e criar estratégias para promover e garantir sua inclusão no sistema escolar.

Assim, são colocadas em evidência a governamentalidade, o controle e a normalização empreendidas nas práticas educacionais inclusivas. O profissional responsável pelo AEE passa a fazer parte desta economia de mercado, funcionando como uma engrenagem que faz funcionar a maquinaria da inclusão. Professores, alunos e políticas fazem parte de um círculo de poderes e saberes onde todos dependem dos demais e cada um exerce sua função no sistema.

\section{Referências}

BAUMAN, Z. Modernidade líquida. Rio de Janeiro: Jorge Zahar, 2001.

BRASIL. Política nacional de educação especial na perspectiva da educação inclusiva. Brasília: MEC/SEESP, 2008.

. Resolução No 4, de 2 de outubro de 2009. Brasília: MEC, 2009.

DELEUZE, G. Foucault - Tradução Claudia Sant'Anna Martins. São Paulo: Brasiliense, 2006.

FERREIRA, A. B. H. Novo dicionário eletrônico aurélio. Positivo Informática, 2004.

FIMYAR, O. Governamentalidade como ferramenta conceitual na pesquisa de políticas educacionais. Educação \& Realidade. v. 34, n. 2. Porto Alegre: Universidade Federal do Rio Grande do Sul, Faculdade de Educação, maio/ago. 2009.

FOUCAULT, M. Do governo dos vivos: curso do Collège de France, 1979-1980 (excertos). São Paulo: Centro de Cultura Social; Rio de Janeiro: Achiamé, 2011. 
FOUCAULT, M. Microfísica do poder. Rio de Janeiro: Graal, 1992.

. O sujeito e o poder. In: RABINOW, P.; RABINOW, H. Michel Foucault: uma trajetória filosófica (para além do estruturalismo e da hermenêutica). Rio de Janeiro: Forense Universitária, 1995.

. Vigiar e punir: nascimento da prisão. Petrópolis: Vozes, 2009.

GALLO, S. Uma apresentação: diferenças e educação; governamento e resistência. In: LOCKMANN, K.; TRAVERSINI, C. S. Saberes morais, psicológicos, médicos e pedagógicos e seus efeitos na inclusão escolar. In: THOMA, A. S.; HILLESHEIM, B. Políticas de inclusão: gerenciando riscos e governando as diferenças. Santa Cruz do Sul: EDUNISC, 2011.

LOPES, M. C. Políticas de inclusão e governamentalidade. In: Educação \& Realidade. v. 34, n. 2. Porto Alegre: Universidade Federal do Rio Grande do Sul, Faculdade de Educação, maio/ ago. 2009 .

Problematizando os discursos que constituem a metanarrativa da inclusão escolar. Disponível em <http://www.humanas.unisinos.br/siapea/textos.htm>. Acesso em: 12 set. 2012.

MENEZES, E. C. P. A maquinaria escolar na produção de subjetividades para uma sociedade inclusiva. Tese (Doutorado em Educação) - Programa de Pós Graduação em Educação, Universidade do Vale do Rio dos Sinos, 2011.

NEUTZLING, I.; RUIZ, C. M. M. B. (Orgs.). O (des) governo biopolítico da vida humana. São Leopoldo: Casa Leiria, 2011.

ROSE, N. Cérebro, self e sociedade: uma conversa com Nikolas Rose. Physis Revista de Saúde Coletiva. Rio de Janeiro, n. 20, 2010.

VEIGA-NETO, A. Biopoder e dispositivos de normalização implicações educacionais. In: VEIGA-NETO, A. Foucault \& a Educação. 3. ed. Belo Horizonte: Autêntica, 2011.

VEIGA-NETO, A.; LOPES, M. C. Inclusão e governamentalidade. Educação e Sociedade. v. 28, n. 100 - Especial. Campinas, out. 2007.

\section{Notas}

\footnotetext{
${ }^{1}$ Destacamos aqui que a escolha pelo verbo tensionar se dá no sentido de intentarmos constituir tensão. A pretensão não se faz na perspectiva de buscar tencionar, planejar ou projetar.

${ }^{2}$ Institui Diretrizes Operacionais para o Atendimento Educacional Especializado na Educação Básica, modalidade Educação Especial.

3 "Regime de verdade é [...] aquilo que constrange os indivíduos a esses atos de verdade, aquilo que define, que determina a forma desses atos; é aquilo que estabelece para estes atos condições, efetuações e efeitos específicos"(FOUCAULT, 2011, p. 77).

4 "Tal maquinaria ao ser institucionalizada, tem no Estado uma fonte de energia que instaura seus movimentos. Tais movimentos são transmitidos por um conjunto de engrenagens a um conjunto de máquinas que, uma vez em operação, buscam ao final a produção de sujeitos dentro de padrões estabelecidos em cada tempo. Essas máquinas podem ser compreendidas pelo conjunto de práticas desenvolvidas no interior da escola que, engendradas umas nas outras, produzem esse sujeito idealizado" (MENEZES, 2011, p. 82).

${ }^{5}$ Para constar, a referida Política prevê como sujeitos por ela governados, os deficientes, os superdotados ou com altas habilidades e aqueles com transtornos globais do desenvolvimento.

${ }^{6}$ Utilizamos o adjetivo inclusivo para caracterizar os sujeitos, tendo em vista a sua condição de inclusão como estado, necessitando de ser conquistado permanentemente.
} 
${ }^{7}$ A partir daqui utilizaremos o termo Política (com "P" maiúsculo) para designar a Política Nacional de Educação Especial na perspectiva da Educação Inclusiva (2008).

* Doutoranda em Educação pela Universidade do Vale do Rio dos Sinos, São Leopoldo, Rio Grande do Sul, Brasil.

** Doutoranda em Educação nas Ciências pela Universidade Regional do Noroeste do Estado do Rio Grande do Sul, Ijuí, Rio Grande do Sul, Brasil.

\section{Correspondência}

Patrícia Gräff - Faculdades Alternativas de Santo Augusto, Departamento de Educação. Rua Francisco Fuciline, 485, Santa Fé, CEP: 98590-000 - Santo Augusto, Rio Grande do Sul, Brasil.

E-mail: patigraff@yahoo.com.br - danimedeiros10@yahoo.com.br

Recebido em 19 de junho de 2014

Aprovado em 11 de dezembro de 2015 